\title{
Biological invasions: winning the science battles but losing the conservation war?
}

Philip E. Hulme

\begin{abstract}
Biological invasions by non-indigenous species (NIS) are widely recognized as a significant component of human-caused global environmental change. However, the standard programme of mapping distributions, predicting future ranges, modelling species spread, assessing impacts, developing management guidelines and screening species suffers from a number of serious limitations. NIS distribution maps can often be as misleading as they are instructive. Perceptions of the intensity, scale and rate of invasion are a function of mapping resolution, and the lack of common mapping standards prevents accurate comparative assessments. Coarse resolution data may overestimate the role of climate in the invasion process relative to other variables such as land use or human population density. Climate envelopes have therefore been widely used to predict species future ranges, but often overestimate potential distributions. Without an appropriate mechanistic understanding of the invasion process, correlative approaches may misinterpret the relative risks posed by different NIS. In addition, statistical models of invasion fail to encapsulate the complexity of human-mediated dispersal, which includes such diverse processes as transatlantic
\end{abstract}

timber trade, horticultural fashion and the continuing expansion of road networks. Screening tools based on species traits, taxonomy and/or invasion history can sometimes result in high discrimination rates. Yet where the cost of false positives outweighs the risks from false negatives, a higher discriminatory power is required. Certain research outputs have perhaps been counterproductive in the war against invasive species. Studies have highlighted that only a tiny proportion of NIS are invasive, that most invasions occur in human dominated rather than pristine ecosystems, that indigenous and non-indigenous species are sufficiently similar that their impacts may not necessarily be different, and that there is evidence that introduced species augment rather than reduce species diversity. It is crucial to address these wider perceptions of the problem in order to mobilize the resources necessary for a global invasive species management programme.

Keywords Aliens, biodiversity, ecosystem impacts, exotic species, management, maps, models, non-indigenous species.

\section{Introduction}

Biological invasions by non-indigenous species (NIS) are widely recognized as a significant component of human-caused global environmental change, often resulting in a significant loss in the economic value, biological diversity and function of invaded ecosystems. The significance of invasions to global conservation efforts has generated considerable empirical and theoretical advances. The fruits of these labours have spawned a vast literature, and recent reviews cover population biology (Sakai et al., 2001), ecological (Parker et al., 1999; Mack et al., 2000) and economic (Pimentel et al., 2001) impacts, as well as research needs (Ewel et al., 1999;

Philip E. Hulme NERC Centre for Ecology and Hydrology, Banchory, Kincardineshire, AB314BW, UK. E-mail: pehu@ceh.ac.uk

Received 29 October 2002. Revision requested 3 February 2002. Accepted 25 March 2003.
Byers et al., 2002) relating to biological invasions. Edited volumes have drawn together expertise on global change (Mooney \& Hobbs, 2000), economics (Perrings et al., 2000; Pimentel, 2002) and management (Brundu et al., 2001; McNeeley, 2001) to address biological invasions. The issues have also fired the public's imagination and generated popular assessments of invasive species problems (Bright, 1998; Baskin, 2002). Although NIS invasions have never before received such a high profile, apart from a handful of examples using biological control (McFadyen, 1998), it is not evident that the current scientific outputs have had any noticeable impact in turning the tide of biological invasions. While this is partly a result of the vast scale of the problem, it also reflects that many of the approaches and perspectives addressing biological invasions, while excellent at highlighting the problems, are less successful at generating solutions. The thesis presented here is that the standard programme of mapping distributions, predicting future ranges, modeling species spread, assessing impacts, 
developing management guidelines and species screening suffers from a number of serious limitations. Until these are adequately addressed progress towards arresting biological invasions will be limited.

\section{Lies, damned lies and maps}

A key requirement for the effective management of invasive plants is the ability to identify, map, and monitor invasions (Ewel et al., 1999). Moreover there exists an urgent need to assess the extent of biological invasions worldwide (Mack et al., 2000). Unfortunately, there are no common standards in terms of sample units (e.g. points, systematic grids, or political boundaries), data collected (e.g. species occurrence, species presence and absence, or relative abundance), spatial extent (e.g. regional, national or continental) and resolution of the maps thus generated. This absence of common standards leads to a profusion of different maps that rarely facilitate comparison. Furthermore, biological invasions are dynamic, large-scale phenomena and the spatial resolution and extent of a species map determine the degree to which the data are of use in addressing key issues in invasion ecology. This is especially of concern in any attempt to characterize the spatial pattern of invasive species, identify invasion hotspots and predict rates of spread.

As expected, there is often a decrease in data resolution with increasing spatial extent. For example, the plant distribution data for Europe $\left(10,382,000 \mathrm{~km}^{2}\right)$ are currently mapped on a $50 \times 50 \mathrm{~km}$ resolution grid (Jalas \& Suominen, 1972-1994), whilst for the British Isles $\left(244,872 \mathrm{~km}^{2}\right)$ these data are available on a $10 \times 10 \mathrm{~km}$ resolution grid (Preston et al., 2002a), and within the British Isles, county floras (e.g. Montgomeryshire, UK, $2,356 \mathrm{~km}^{2}$ ) may be mapped on a $2 \times 2 \mathrm{~km}$ resolution grid (Trueman et al., 1995). The trade-off between spatial extent and data resolution found in most species distribution maps constrain their utility. For example, Japanese knotweed Fallopia japonica, a noxious invasive weed of Asian origin, is widespread in both Europe and the USA (Fig. 1). Examination of the coarse state-by-state distribution across the USA reveals that 40 out of 49 coterminous states have been invaded by the species, potentially over two-thirds of the USA. Although an impressive map, likely to shock policy makers into action, it is misleading. Examination of individual state maps reveals a markedly different trend. The major hotspots of invasion are in New England and the Midwest. Elsewhere F. japonica occurs only occasionally, and this is especially true for the central states. Coarse resolution maps of species presence and absence will tend to overestimate the extent of spread and fail to describe adequately the spatial structure of invasions. They are therefore of little practical use in depicting spatial trends or targeting management. At such coarse resolutions, maps should as a minimum represent comparative indices of relative abundance in order to be of any value. The individual states of the USA are a particularly coarse recording unit, comparable in size to European nations. In Europe, a $50 \times 50 \mathrm{~km}$ systematic grid (an equivalent scale to most US counties) highlights a more precise representation of F. japonica distribution (Fig. 1b). At this resolution, a western core to the species distribution is evident with more sparse occurrences to the north, south and east. Thus, while it is not surprising that finer resolution distributions are more informative, it is often forgotten how misleading coarse resolution maps can be.

The spatial resolution of data not only influences the interpretation of species distributions but also spatial dynamics. Comparison of the spread since 1900 of three invasive riparian non-indigenous species in the British Isles reveals the characteristic features of a lag-phase followed by exponential expansion and subsequent deceleration (Fig. 2). These characteristics are evident whether assessed at a hectad $(10 \times 10 \mathrm{~km})$ or vice-county (c. $50 \times 50 \mathrm{~km})$ resolution. Nevertheless, the area occupied is inflated at the coarser resolution (particularly for the sparsely distributed Heracleum mantegazzianum) and vice-county data depict a shorter and less marked lagphase, a more marked phase of increase and a clear plateau in the final phase. Thus at coarse resolutions the temporal trajectories of invasions overestimate both the area occupied and rate of spread.

When combined with spatial data on climate, soil and/or vegetation, NIS maps can present opportunities to study the factors underpinning invasive species distributions (Franklin, 1995). For terrestrial plants, a hierarchical scheme of environmental controls on species distributions has been suggested in which climatic variables correspond to patterns at the largest spatial scales (e.g. $50 \times 50 \mathrm{~km}$ or more), followed by geology (and its effect on soil chemistry and nutrient availability) and topography (at $10 \times 10 \mathrm{~km}$ ), which moderates many of the macroclimatic variables (Franklin, 1995). An understanding of the interplay among processes operating at different spatial, and necessarily temporal, scales will identify their relative importance and emphasize the most appropriate scale at which to predict future changes to the system (May, 1989).

Collingham et al. (2000) examined the degree to which environmental variables were successful at predicting the presence/absence of three NIS at two spatial scales in the UK. Four aspects of the predictive models were scale-dependent: a) the goodness of fit of the predicted values to the observed distributions, b) the optimum threshold for species presence, c) the significance of 


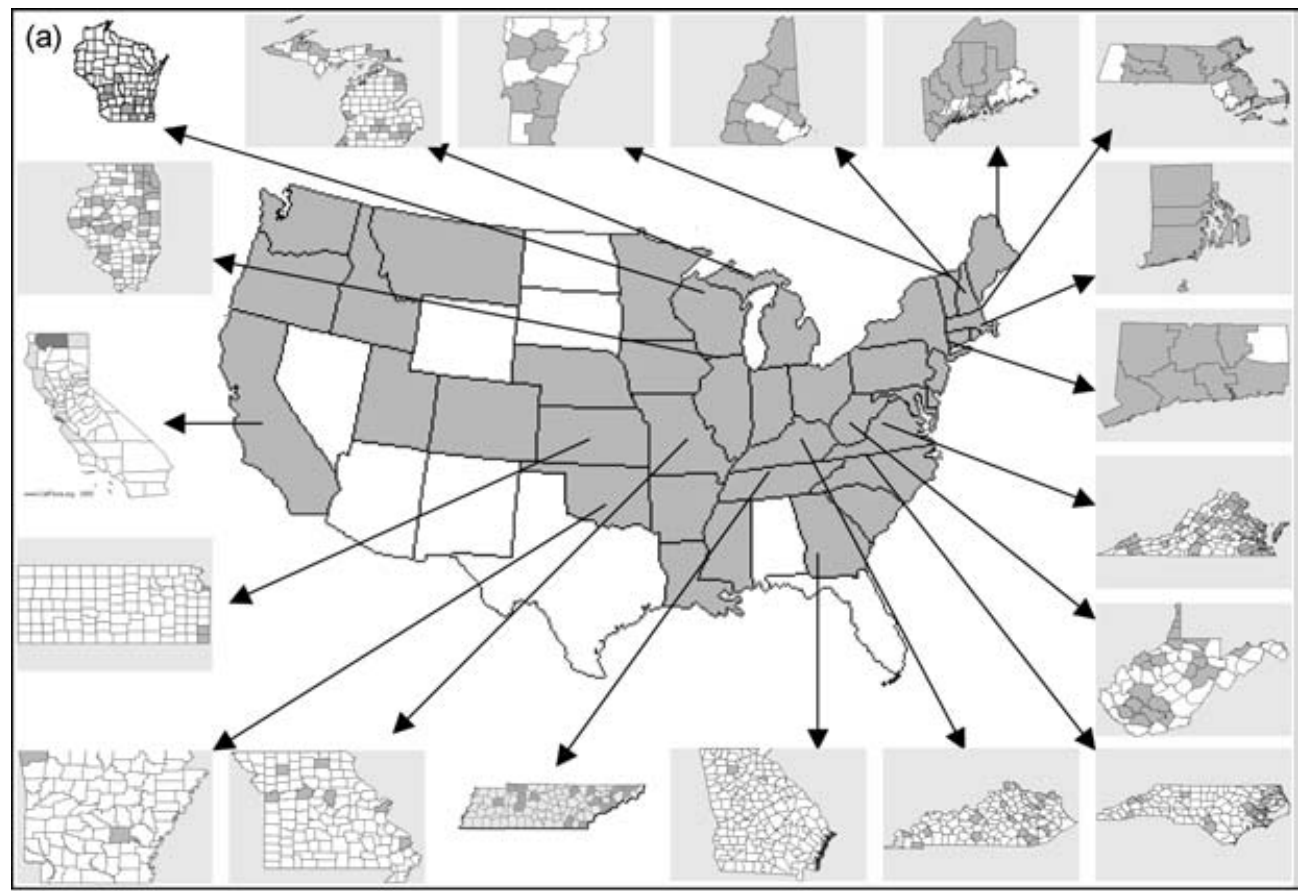

(b)

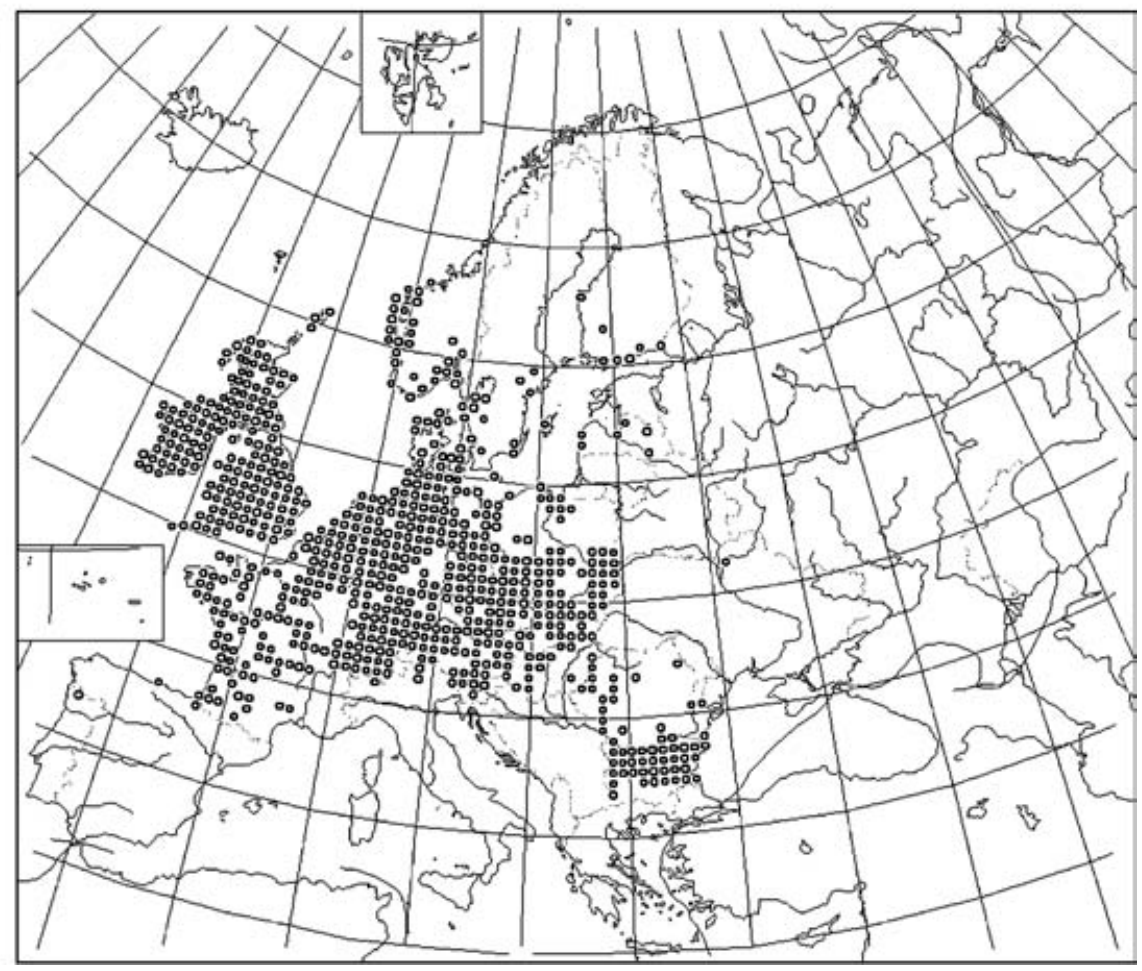

Fig. 1 Distribution of Fallopia japonica in a) the coterminous states of the USA (reproduced with permission of The PLANTS Database (USDA \& NRCS, 2002), and b) Europe (reproduced from Atlas Flora Europeae (Jalas \& Suominen, 1972-1994), with permission.

spatial autocorrelation, and d) the environmental variables included in the best fit model. The study did not reveal marked hierarchical controls on species distribution but did highlight that to ensure correspondence with environmental drivers (e.g. soil, geology and climate data), mapping should be undertaken at an equivalent or smaller spatial resolution. At smaller spatial scales (e.g. $2 \times 2 \mathrm{~km}$ ) the degree of spatial autocorrelation was 


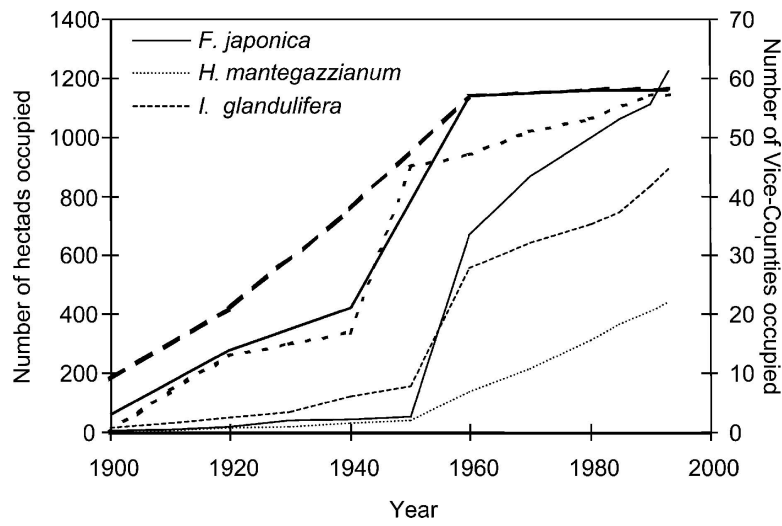

Fig. 2 The rate and extent of spread of Fallopia japonica, Heracleum mantegazzianum and Impatiens glandulifera as measured by the cumulative number of hectads $(10 \times 10 \mathrm{~km}$ squares $)$ (bold lines) and the cumulative number of vice-counties (fine lines), occupied since 1900 in England and Wales. Data are from the Biological Records Centre, Monks Wood, UK.

found to be an important determinant of species distributions. The distribution of an invasive species spreading across a landscape may be expected to exhibit spatial autocorrelation because the probability that an area will be colonized will be a function of its distance from neighbouring populations. In general the scale over which spatial autocorrelation occurs will reflect the dispersal efficiency of the invading species and thus is expected to be more evident at finer spatial scales.

A cynic may argue that the interpretation of invasive species distributions is entirely context dependent and the arbitrary choice of spatial resolution will determine the perceived range, spatial distribution, rate of spread and environmental drivers. Thus, to impress policy makers it may be preferable to plot NIS distributions at coarse spatial resolutions in order to highlight fast spreading, wide-ranging, climate driven invasions. However, while fine resolution mapping is considerably more informative, it is exceedingly costly and time consuming to apply to large areas. Is there an alternative?

If the principal aims of mapping are to characterize spatial pattern, predict rates of spread and assess relationships between spatial extent and abundance, then it may not be necessary to produce a complete cartographic coverage of species distributions. Indeed, repeat sampling of specific points across a large geographical area may be far more useful in terms of monitoring invasions and targeting management. This issue can once again be illustrated with the distribution of F. japonica in the UK. Systematic grid-based (c. $300010 \times 10 \mathrm{~km}$ cells) floristic surveys reveal the species to be sufficiently widespread (Fig. 3a) that most administrative regions face an uphill struggle in any attempts to manage the species. However, a stratified survey of relative abundance drawn from a single sample of riverbanks in each $10 \times 10 \mathrm{~km}$ cell presents an altogether different picture (Fig. 3b). Although such a survey does not pick up every cell where F. japonica occurs, it nevertheless provides a clearer indication of where invasion is most prevalent. This is precisely the information required for management. Furthermore, by stratifying samples over a large area but maintaining the fine resolution, the data can be
Fig. 3 Distribution of Fallopia japonica in Great Britain as described by a) systematic grid $(10 \times 10 \mathrm{~km})$ cell surveys (reproduced with permission from Beerling et al., 1994), and b) stratified samples from the UK River Habitat Survey (reproduced with permission from Dawson \& Holland, 1999).

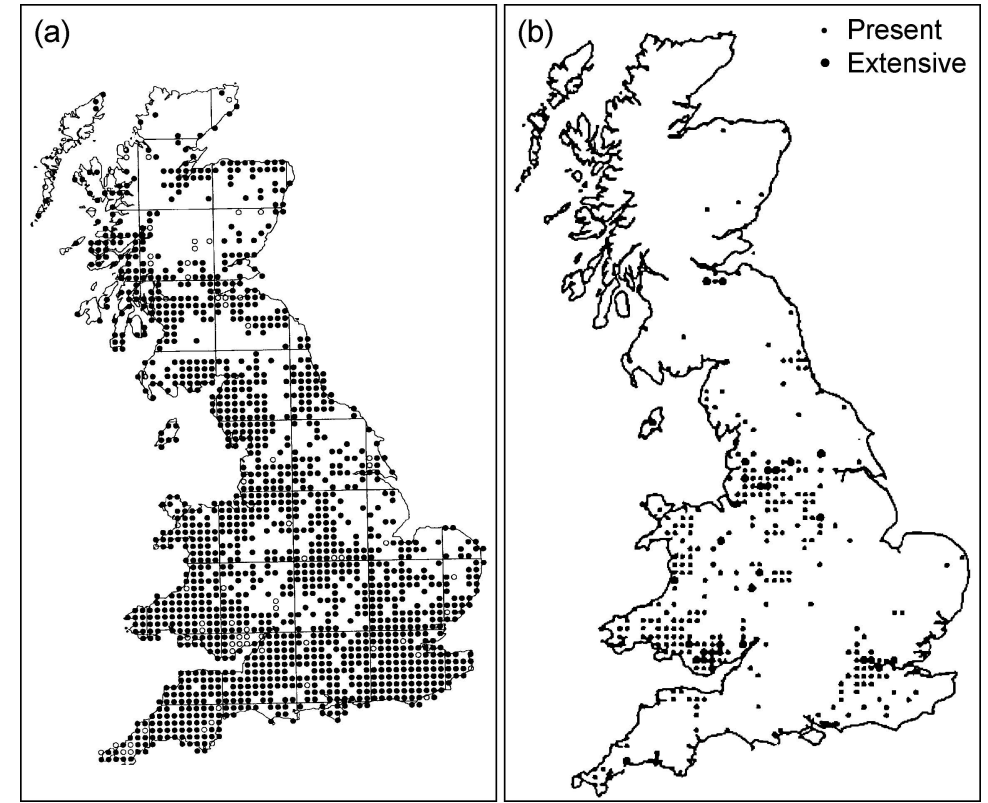


used as a basis for modelling the species occurrence in unsampled sites (Collingham et al., 2000). By recording abundance at fixed sites over time, the rate of spread both locally and regionally can be accurately monitored. While this approach may not be free of problems, it is still relatively costly and requires targeting of invaded habitats; it nevertheless appears to be a suitable compromise for the problems inherent in trading off spatial extent and data resolution.

\section{Climate envelopes: return to sender?}

Climate plays a primary role in determining the geographic distributions of plants (Woodward, 1987). Several attempts to predict NIS distributions in the introduced range have relied on the 'climate envelope' approach (Panetta \& Mitchell, 1991; Beerling, 1993; Beerling et al., 1995; Higgins et al., 1996). In this approach either the current distribution of a species in its native or introduced range is mapped in climate-space and then used to predict the potential expansion in the introduced range. Although intuitively appealing, this approach has been criticized because other factors (e.g. interspecific interactions) may constrain species distributions (Davis et al., 1998; Lawton, 2000). While it is widely recognized that climate is not the only determinant of a species' range (Woodward, 1987), climate envelopes are often used to assess the potential range of a species. However, even this 'Null Hypothesis' that climate envelopes identify the potential range is viewed with scepticism (Lawton, 2000).

Current ranges whether in the native or introduced regions are unlikely to be determined solely by climate. In the native range the species is likely to interact with natural enemies and competitors that constrain a species' distribution. By eliminating enemies and competitors it is often possible to grow plants well outside their normal environments. This is precisely why many invasive plants do so well in their introduced ranges (Maron \& Vila, 2001). Geographical barriers such as mountains, major rivers and highly fragmented landscapes may limit dispersal sufficiently that species do not reach their climatic limits. Indeed, attempts to fit climate envelopes often identify these failings. Using the European distribution of F. japonica (Fig. 1b), Beerling et al. (1995) attempted to simulate the distribution of the species in its native Asian range. While the study is often cited as an example of how climate envelopes can be used to predict invasion, the study actually revealed that climate envelopes overestimated the species' range because they failed to account for the constraints imposed by mountains, river gorges and interspecific interactions. An additional limitation is that current distributions may be the result of sources and sinks, in which species appear to thrive in places where they in fact persist only because individuals disperse into them from elsewhere (Carter \& Prince, 1988). A further problem exists when using the species distribution in the introduced range as a basis for predicting potential distribution. A fundamental assumption in correlative modelling of species distributions is that species should be in equilibrium with their environment (Franklin, 1995). Where the distributions of NIS are still increasing (e.g. Fig. 3), the non-equilibrium distribution will limit the goodness of fit of predictions in three ways. Firstly, models are likely to perform poorly when species are sparse. Secondly, if a species does not occupy all suitable habitats then it is unlikely that the variables entered into models will be sufficiently comprehensive and thus predictions will be weak. Thirdly, even if the environmental variables capture the essence of the species distribution, models will consistently predict species presence in areas where the species has yet to invade. Thus the closer a species is to maximum potential range, the better the observed goodness of fit. Thus attempts to model the distribution of NIS in both New Zealand and the British Isles have identified locations predicted as suitable that have as yet not been colonized due to limited rates of dispersal (Wilson et al., 1992; Collingham et al., 2000). Comparison of climate envelope predictions with experimental sowing of Impatiens glandulifera and H. mantegazzianum beyond the species' current distribution in the British Isles has revealed that proposed climate thresholds do not coincide with significant reductions in plant performance or finite rate of increase (Willis \& Hulme, 2002). Therefore, while climate may set an absolute limit on species' distributions, the demographic evidence suggests that the two species have not reached these limits at present.

Given these problems, why do climate envelopes continue to be used to model species invasions (e.g. Peterson \& Vieglais, 2001, Sykes, 2001; Bakkenes et al., 2002)? The answer relates back to the issue of spatial extent and resolution of species distributions. Climate envelopes are usually generated as a means of making predictions at regional scales where both species and environmental data are available at relatively coarse resolutions. Over such large spatial extents, climate data are often the only environmental variables that are either systematically recorded or can be interpolated at regional scales. However, the availability of these data does not necessarily imply they are of unique importance. While climate plays a significant role in determining species distributions at both fine and coarse resolutions, variables such a human population density, land use and geology are also similarly, if not more, important (Collingham et al., 2000). Wider recognition of the errors 
inherent in using climate envelopes will hopefully lead to more robust analyses integrating a wider range of variables and, as a consequence, a better understanding of biological invasions.

\section{Tails of the unexpected}

Static models of NIS distributions, whether based exclusively on climate or preferably on a wider range of explanatory variables, provide a platform for assessing the degree and extent to which an area may be susceptible to invasion. However, to estimate the probability and rate of invasion requires modelling a species' spatial dynamics. Considerable advances have been made in the development of models of invasions (Higgins \& Richardson, 1996). Whether based on reaction-diffusion, cellular automata or metapopulation approaches, the upshot is that no matter how well parameterized demographic parameters may be, models are most sensitive to the accurate quantification of dispersal. It is the rare, long-distance dispersal events that have been the most difficult to parameterize. A single dispersal function (be it negative exponential or bivariate normal) cannot successfully describe both local expansion and the long tail necessary to describe long-distance colonization. Models have therefore attempted to simulate dispersal as two or more different processes (e.g. Allen et al., 1991; Collingham et al., 1997; Higgins \& Richardson, 1999; Wadsworth et al., 2000). Whilst local dispersal can be estimated from mechanistic models or contemporary studies of seed deposition, long-distance dispersal events are rarely observed and often parameterization relies on 'ball park' figures of both frequency and distance. While palaeoecologists are keen to promote the power of natural events to generate long-distance dispersal events (Clark et al., 1998), it has become increasingly evident that human activities (both deliberate and accidental) are responsible for long-distance NIS dispersal (Hodkinson \& Thompson, 1997). It is unlikely that statistical models will encapsulate the complexity of human-mediated dispersal, which includes such diverse processes as transatlantic timber trade, horticultural fashion and the continuing expansion of road networks. Long-distance dispersal spectra no longer necessarily reflect attributes of an invader's life-history, and both the distance and frequency are unlikely to be constant, but more worryingly actually increase as a result of global trade and economic development.

A glimpse of what human mediated dispersal spectra may look like can be estimated from the initial colonization of the British Isles by I. glandulifera and F. japonica early in the 20th century. The recorded locations of each species in 1900 provide a basis for assessing the frequency of colonization events that gave rise to new locations in 1920. If these new locations are assumed to have arisen from locations recorded in 1900, then distances between the nearest source and new locations in 1920 provide an estimate of long-distance dispersal events. Examination of nearest neighbour locations assumes a conservative dispersal process but the results highlight that dispersal to sites over $100 \mathrm{~km}$ is not uncommon (Fig. 4). Median dispersal distances of 20 and $30 \mathrm{~km}$ are found for I. glandulifera and F. japonica, respectively, yet $F$. japonica reveals proportionally more localized spread $(c .10 \mathrm{~km})$ than I. glandulifera. Although the timescale is relatively coarse at 20 years it is inappropriate to summarize dispersal distances as rates per year. The estimated dispersal distances likely represent single events rather than numerous shorter 'steps' because it is highly unlikely that all intervening populations would have gone extinct as the species range was increasing. Thus, it is more appropriate to estimate maximum frequencies of long-distance dispersal per original 'population' (colonized $10 \times 10 \mathrm{~km}$ cell) per year than an annual rate of spread. Such figures reveal particularly high probabilities of long-distance $(>20 \mathrm{~km})$ dispersal events (0.1 and 0.5 per year for I. glandulifera and F. japonica respectively). While such values should be treated with a certain amount of caution they do indicate that long-distance dispersal may be more frequent than expected (e.g. Wadsworth et al., 2000) and that these probabilities can differ markedly among species. It should be remembered that these dispersal spectra reflect human mediated processes during the

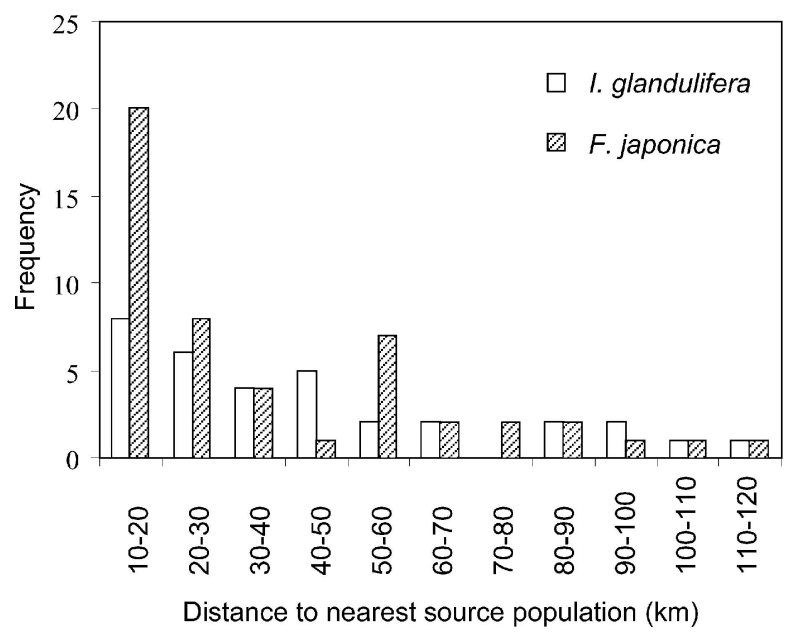

Fig. 4 Estimated distances between populations recorded for the first time in the UK in 1920 and the nearest source population recorded in 1900 for Impatiens glandulifera and Fallopia japonica (data from the Biological Records Centre, Monks Wood, UK). The distribution provides an estimate of the frequency of long-distance ( $>20 \mathrm{~km}$ ) dispersal events. 
first 20 years of the 20th century; such processes are likely to be considerably different during the first 20 years of the 21st century.

\section{Spray and pray doesn’t pay}

Herbicides (e.g. foliar sprays or stem injection) and mechanical removal (e.g. cutting or burning) represent the primary agents for most non-indigenous plant management, even with increasing improvements in biological control (McEvoy \& Coombs, 1999; Headrick \& Goeden, 2001). However, the continued spread of NIS across continents indicates that there have been relatively few occasions where NIS have been effectively eradicated at more than a local scale (but see McFadyen, 1998; Van Wilgen et al., 2001 for examples of successful large-scale management). Partly this is a result of control measures not being implemented until a species becomes a problem, by which stage they are expensive to control and require extensive research into the ecological, economic and political aspects of management (OTA, 1993; Wadsworth et al., 2000). The direct costs of control programmes can be high and therefore require considerable investment and planning. In the USA c. US \$1.5-2.3 billion spent annually for herbicides in the agricultural sector can be attributed to NIS management. Even for individual species, costs can be high. For example, in the UK average costs for $H$. mantegazzianum control in 1989/90 were US $\$ 1,500 \mathrm{ha}^{-1}$ for materials alone (Sampson, 1994) while total costs of eradicating Crassula helmssii is estimated at US \$5 million (PlantLife, 2000). For particularly pernicious species such as Rhododendron ponticum costs can be as high as US $\$ 90,000 \mathrm{ha}^{-1}$ (Compton \& Key, 1998) and cumulative costs for large areas such as Snowdonia National Park can total US \$70 million (Gritten, 1995). Similar figures from the USA quote annual costs for Lythrum salicaria and Hydrilla vericiliata control to be US $\$ 45$ million and US $\$ 14.5$ million respectively (Pimentel et al., 2001). Given that the resources available for control measures are limited, it is clearly desirable to develop an explicit strategy for identifying priority areas for control.

Moody \& Mack (1988) suggested that from a population dynamics perspective, it is best to eradicate small outlying populations because they contribute most to range expansion (Fig. 5a). The subsequent 'rule of thumb', to prioritize control of satellites before the core populations, has proved popular (Masters \& Sheley, 2001). In contrast, metapopulation dynamic considerations suggest that control should focus instead upon the larger core population(s) that supply the majority of propagules. If larger populations are likely to contribute proportionally more to long-distance dispersal and
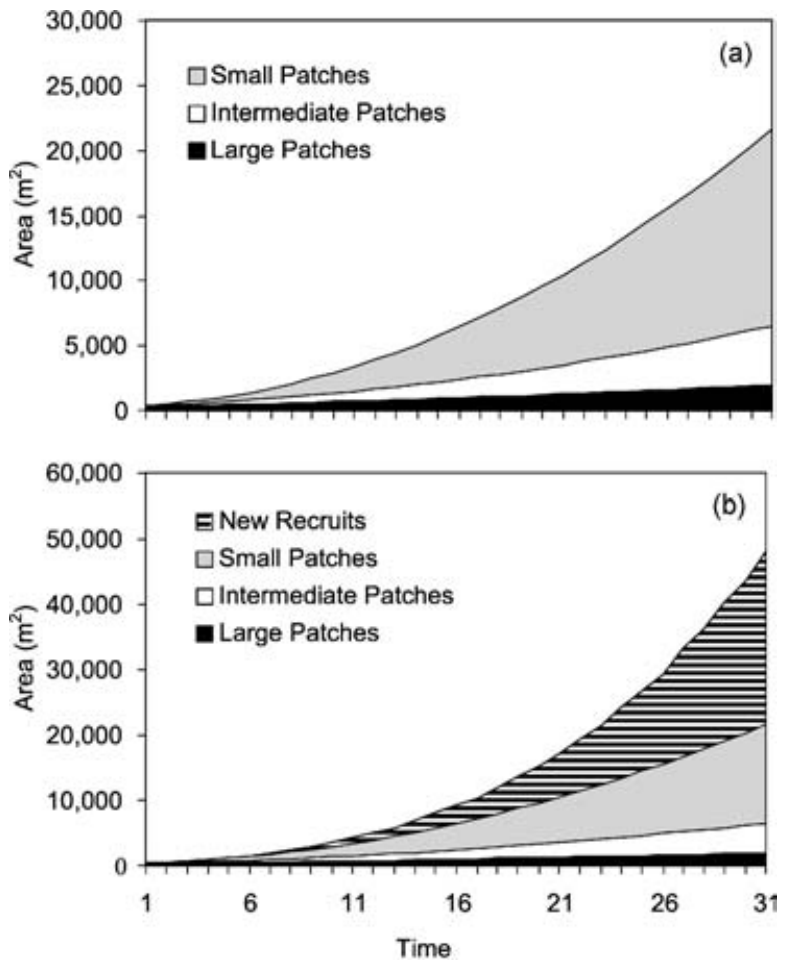

Fig. 5 The predicted rate of spread of a model non-indigenous species arising from small $\left(\right.$ c. $\left.1 \mathrm{~m}^{2}\right)$, intermediate $\left(c .10 \mathrm{~m}^{2}\right)$ and large $\left(c .300 \mathrm{~m}^{2}\right)$ plant 'patches'. Without recruitment (a) reveals that spread from small satellite patches contribute most to the area covered by the species and thus these should be prioritized for control. However, if recruitment is included in the model (b) then most spread occurs through recruitment of juveniles, and if propagule supply is a function of patch size then large 'source' patches should be prioritized for control. Note the different scales for a) and b).

the generation of additional satellite populations, then management should be directed at the core (Fig. 5b). For invasive plants in riparian systems, the normal recommendation is to tackle upstream populations first and then work downstream, although sometimes the opposite strategy is adopted because vegetative growth begins earlier near the sea (Tiley \& Philp, 1994). However, in practice most control is sporadic and aimed at wherever the problem is perceived to be greatest, such as in amenity areas and nature reserves (Dodd et al., 1994). Assessing the relative merits of different approaches is hindered by the limited data available on the efficiency (number of plants completely eradicated) of control efforts or the persistence of their effect following treatment (but see Caffrey, 2001).

Only recently have decision tools been developed to assess the relative success of different management strategies against NIS. Wadsworth et al. (2000) examined five representative control strategies against I. glandulifera and H. mantegazzianum that prioritized herbicide spraying, 
as follows: at random, in relation to human population density, or by the size, age or spatial distribution of weed populations. These strategies were assessed at different intensities of management (area treated per year) and for varying efficiency (proportion of plants destroyed) as well as timeliness (how long since the species became established) of implementations. Strategies that prioritized control on the basis of weed population characteristics were most effective, with plant population size highlighted as a key parameter. The reduction in geographic range within a catchment or region following control was always greater for $H$. mantegazzianum than for I. glandulifera due to the former's slower rate of spread (Fig. 6). Higgins et al. (2000) evaluated strategies for the control of woody species in South Africa in terms of the cost of the clearing operation, the time to eradicate the plants, and the impact the plants have on native plant diversity. Clearing strategies that prioritized lowdensity sites dominated by juvenile alien plants proved to be the most cost effective. Strategies that used information on the distribution of plant diversity were not much more expensive than the most cost-effective strategy, and they substantially reduced the threat to native plant diversity. Delaying the initiation of clearing operations had a strong effect on both the eventual costs of the clearing operation and the threat to native plant diversity. These examples highlight the value of decision modelling approaches to ensure more cost-effective NIS control and the requirement for fine-scale data on species distribution in management. They also reveal that there are no simple rules of thumb that can be used to manage

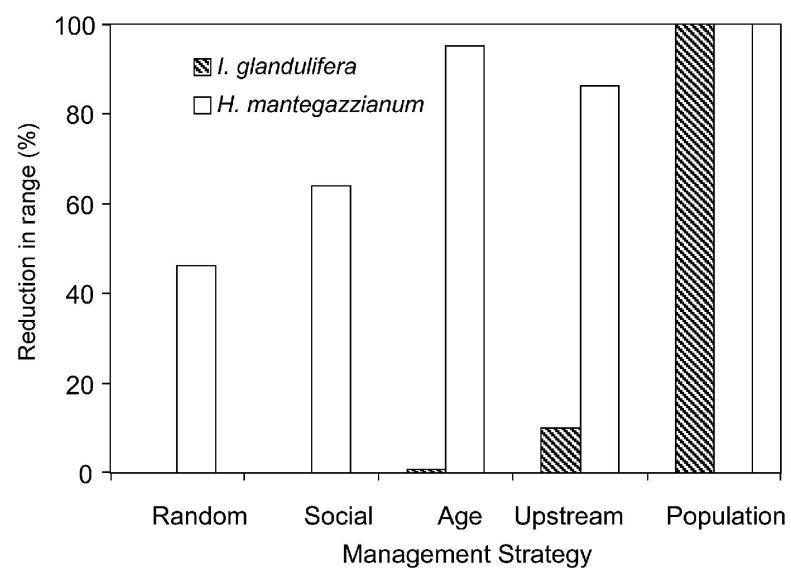

Fig. 6 Differential success of five management strategies in their ability to reduce the ranges of Impatiens glandulifera and Heracleum mantegazzianum in a single river catchment. The management strategies prioritized herbicide spaying as follows: at random, in relation to the proximity to human populations (social), the length of time that a particular site had been invaded (age), upstream populations targeted before those further downstream (upstream), or largest populations targeted first (size). the huge variety of NIS and invaded ecosystems. The true test of these decision tools will be how they fare when used in large-scale management programmes.

\section{Flaws in the laws}

Given the considerable constraints in targeting and undertaking NIS control or eradication once species have become established, a solution may be to prevent the introduction of invasive species in the first place. Ideally, a cost-effective, simple-to-use screening toolkit based on robust risk assessment criteria would represent a substantial weapon in the war against invasive species. Unfortunately, the reality is still far from the ideal. Numerous attempts to use biological traits, habitat compatibility, taxonomy and/or stochastic measures (initial population size, residence times and number of introduction events) have met with mixed results (Rejmánek et al., in press). A posteriori screening of naturalized plants in Hawaii using systems developed specifically for South Africa, North America, and Australia generated 60, 82 and 93\% correct predictions regarding invasive status respectively (Daehler \& Carino, 2000). The latter two predictions appear impressive, but are not without problems. Decision theory analysis highlights that a pest risk assessment system with an accuracy of $85 \%$ would be better ignored, unless the damage caused by introducing a pest is eight times that caused by not introducing a harmless organism that is potentially useful (Smith et al., 1999). Undeniably, knowledge of the factors responsible for biological invasions has improved considerably, but the Holy Grail of a robust screening tool remains out of reach for most taxa.

No matter how robust the screening system, without appropriate legislative structures failure to implement and enforce risk assessments will seriously constrain their utility. At first glance, appropriate international legislation appears to exist. Signatories of the UN Convention of Biological Diversity have agreed to "eradicate those alien species that threaten ecosystems, habitats or species" (Article 8h). Member States of the European Union have a commitment "to strictly control the introduction of non-indigenous species" (Bern Convention on the Conservation of European Wildlife and Natural Habitats) and both the 'Habitats' and 'Birds' Directives of the European Union also contain provisions to ensure introductions do not prejudice the local flora and fauna (Hulme et al., 2000). However, European legislation: a) is restricted to prevention of deliberate rather than accidental introductions, b) exempts major sources of accidental introductions such as forestry and agriculture species, biocontrol agents, and introductions into zoological and botanical gardens and c) does not include a commitment to eradicate or control established 
non-indigenous species. European States also have a commitment "to report the existence, outbreak and spread of plant pests and of controlling those pests" (UN International Plant Protection Convention). Pests are clearly defined by the convention as "... of potential national economic importance to the country endangered thereby". The 'Plant Pests' Directive of the European Union provides lists of pest species that must be banned from being introduced into particular Member States. The only equivalent directive for animals is the 'Aquaculture' Directive that legislates against the introduction of organisms pathogenic to aquaculture animals. European legislature reveals an acute awareness of the economic and environmental costs of non-indigenous and outbreak species. Identification of target species facilitates the control and eradication of agricultural pests, an aspect missing from the environmental legislation. This reflects the absence of a clear European perspective on the ecological impacts of these organisms on natural ecosystems and the difficulty of controlling accidental introductions.

In the United Kingdom, it is an offence to release or allow to escape any animal that is not ordinarily resident in, or not a regular visitor to the UK. In addition it is an offence to release or allow to escape a number of established non-native plants and animals (HMSO 1981). While the UK has comprehensive regulations dealing with the introduction of non-native animal species, it has proved more difficult to formulate effective legislation to deal with non-native plants and other organisms. The Department of the Environment, Transport and the Regions has published guidelines (DoE, 1997) that explain the procedures needing to be followed before the release of a non-native species. Some legislative measures have been put in place to prevent the arrival of non-native species that may be expected to cause problems for agriculture, forestry or human health, although these do not extend effectively to prevent the arrival of invasive species that may be anticipated to cause problems for native biodiversity. The inconsistencies in international and national legislation have recently been the focus of considerable attention by IUCN and has resulted in revised recommendations for the design of legal and institutional frameworks on alien invasive species (Shine et al., 2000). However, the success of such recommendations and their uptake by national legislative bodies will depend strongly on current perceptions of the problems posed by biological invasions.

\section{Problems of perception?}

"That such aliens devalue the natural landscape is purely a matter of perception and, by ignoring the ever- changing nature of the British flora and vegetation, begs the questions of what this cherished pristine landscape was and when it existed" (Dickson et al., 2000). As this quote illustrates, not all scientists, policymakers and members of the public necessarily share the view of invasion ecologists that biological invasions are considered second only to habitat destruction in their effects on native biota and entire landscapes (Wilson, 1992). The literature supports the thesis that only a tiny proportion of NIS are invasive, that most invasions occur in human dominated rather than pristine ecosystems, that indigenous and non-indigenous species are sufficiently similar that their impacts may not necessarily be different, and that there is evidence that invasion increases rather than reduces species diversity. It is crucial for progress in the field of invasions to address these wider perceptions of the problem in order to mobilize the resources necessary for a global management programme.

\section{Don't most non-native species fail to invade?}

The simple answer to this question is yes, but this should not lead to complacency in managing species introductions. The 'ten's rule' attempts to quantify the transition probabilities of an introduced species becoming a pest (Williamson, 1996). It broadly states that approximately $10 \%$ of all imported species will escape into the environment, $10 \%$ of these escapes will become naturalized and $10 \%$ of naturalized species will prove to be a pest. Testing the generality of this rule is a core element of future research on invasions (Byers et al., 2002). The 'ten's rule' could be interpreted as indicating that the risks of introducing pest NIS is low. However, independently of the difficulties of defining a pest species (Williamson, 1996) examination of transition rates may not be the best basis for future management. In the British Isles, between 80 and $90 \%$ of non-native plant species occupy less than $10 \%$ of the available range, supporting the idea that most species introductions do not result in pest problems (Fig. 7a). However, such a frequency distribution is not static and the ranges of many non-native species continue to increase (Preston et al., 2002b). Among non-native species that occur in less than $10 \%$ of Montgomeryshire (a vice-county in Wales), while indeed there exist static, non-invasive species, the majority of species are on the increase and could potentially influence estimates of the transition from naturalized to pest status (Fig. 7b). A further problem is the validity of the first transition between importation and escape because analyses are retrospective. The considerable lag phases (Fig. 2) during invasions suggest the patterns we observe today are the result of trends in species introduction from over a century ago. It is 

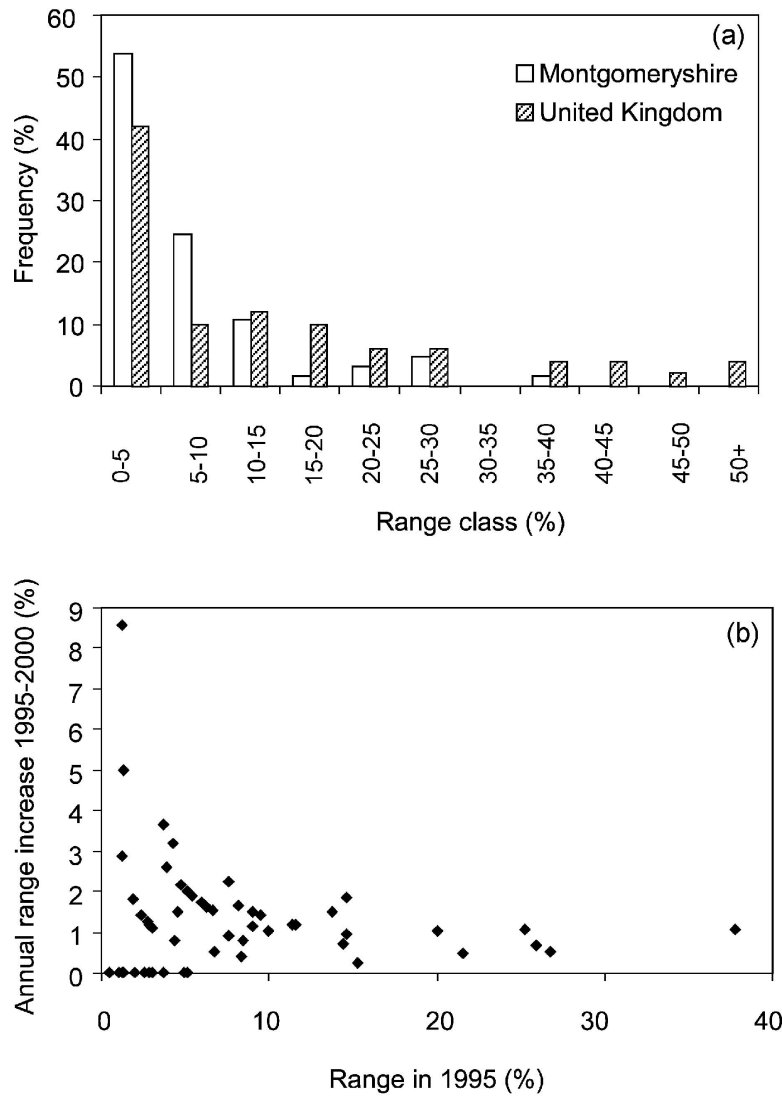

Fig. 7 a) The frequency distribution of range classes of nonindigenous plants in Montgomeryshire (data from Trueman et al., 1995) and the British Isles (data from Perring \& Walters, 1976) revealing that most species have small ranges. $b$ ) The annual range increase of plants in Montgomeryshire between 1995 and 2000 in relation to their original range in 1995.

highly likely that retrospective analyses will underestimate the problem of invasions given the increased globalization of trade, the expansion of the horticultural market and rising human population densities. The 'tens' rule' has been successful at focusing research on the processes leading to invasion but it will fail if it becomes a reifaction rather than a hypothesis.

\section{Don't most invasions occur in disturbed, human dominated habitats?}

A near ubiquitous finding in the search for clues to the differential habitat invasibility is the high frequency of non-native plant species in urban and agricultural environments (Crawley, 1986; Cadotte \& Lovett-Doust, 2001; Fig. 8). It is not that pristine habitats or relatively undisturbed habitats are not invasible (e.g. Mack et al., 2000; Welch et al., 2000; Rejmánek et al., in press), but
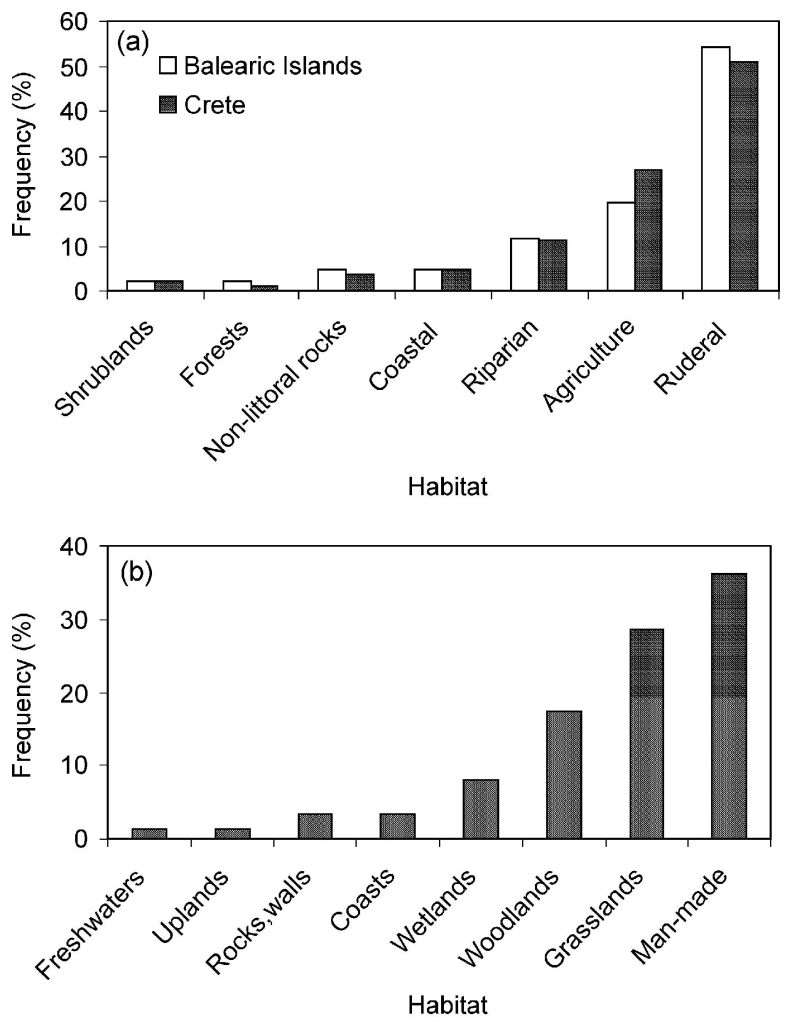

Fig. 8 The frequency of non-indigenous species in different habitats in a) the Balearic Islands and Crete (P. Hulme, unpub.), and b) Scotland (data from Welch et al., 2001) highlighting the high frequency in human dominated habitats.

that human population density is an important determinant of non-native plant distributions (Collingham et al., 2000). Human dominated habitats are likely to have higher rates of species introductions (e.g. from gardens, transport networks, landscaping and crops), a greater proportion of ruderal and disturbed areas, and higher nitrogen inputs from fertilizer, sewage and car exhausts, all of which facilitate invasions (Pysek, 1998a). A sceptic may argue that the rapid and widespread invasion by non-native plants is simply a consequence of the expansion of urban areas and the intensification of agriculture, rather than itself a cause of environmental change. So are invasions of these degraded habitats important?

Human dominated ecosystems still harbour biodiversity, and in the face of urban expansion metropolitan green spaces can represent important species refugia. Often, urban commons such as wasteland habitats are found on post-industrial sites, with substrates that provide environments that are uncharacteristic for towns, resulting in both quantitative and qualitative increases in biodiversity through the addition of rare and unusual floral and faunal elements (Gilbert, 1989). However, 
urban commons, reserves, and green spaces are liable to invasion. The wildlife corridors that run through the city and suburbs of Birmingham, UK, are as susceptible to non-native plant invasion as other urban sites and actually more so for at least four species (including I. glandulifera and F. japonica, Hulme unpub.). Furthermore, urban areas represent important foci for the spread of non-native species into the wider environment, especially neighbouring nature reserves (Pysek et al., 2002). Although the perceived biodiversity losses in intensively managed agricultural areas may be low, the economic costs are often high. Non-native weeds result in annual crop production losses of US \$28 billion in the USA, US \$1.4 billion in the UK, US \$2.4 billion in Australia, US $\$ 1.5$ billion in South Africa, US \$38 billion in India and US $\$ 17$ billion in Brazil (Pimentel et al., 2001). Thus management of plant invasions in human dominated landscapes have clear economic and conservation value.

Ten years ago it was estimated that over one third of the earth's land surface (excluding rocks, barren areas and ice) was human dominated and that little more than a quarter could be truly classified as undisturbed (Hannah et al., 1995). Since 1990, the world population has grown by $20 \%$ and thus if human dominated land use and invasions coincide, then currently much of the earth's land surface is likely to be susceptible to invasions. Therefore, it is perhaps almost more important to understand the dynamics of NIS in human dominated rather than in pristine ecosystems because this will be the key to developing management strategies for future environments.

\section{Aren't indigenous and non-indigenous species ecological equivalents?}

Ecosystems are dynamic and rarely have a single steady state. In this context, biological invasions are an integral element of the natural dynamics of ecosystems and fundamental for the persistence of many species. The ranges of many native weed species have expanded over the last century due to the spread of intensive agriculture, increased urbanization, climate change and eutrophication (Preston et al., 2002b). These drivers have also resulted in the introduction and expansion of NIS (Mooney \& Hobbs, 2000). It appears that it is human activities that are increasing the ranges of commensal species irrespective of their origin. This would explain the positive relationship between indigenous and NIS richness frequently observed at large spatial scales (Levine \& D'Antonio, 1999) and the difficulty in distinguishing expanding species on the basis of their origin (Thompson et al., 1995). If this is the case, then the key issue is do NIS deserve the invective any more than indigenous species? Several authors suggest not because the assignment of qualitative values based on species origin is unscientific and tantamount to xenophobia (Sagoff, 1999; Botkin, 2001; Slobodkin, 2001; Gould, 2002).

Do a priori reasons exist to expect NIS may have greater impacts than native invasive weeds? NIS may interact with a smaller guild of native herbivores (Kennedy \& Southwood, 1984; Brändle \& Brandl, 2001) and/or mutualists (Richardson et al., 2000). This could potentially lead to changes in the food web structure where NIS are dominant. However, there is no consistent evidence that NIS generally differ from comparable indigenous species in stature, resource exploitation, relative growth rate or intrinsic rate of increase (Radford \& Cousens, 2000; Smith \& Knapp, 2001). The key issue is comparability. Several of the most pernicious invasive species belong to families that are not represented in the introduced range, such as Cactaceae in Australia, Pinaceae in South Africa, Agavaceae in the Mediterranean Basin, Tamaricaceae in North America, and Simaroubaceae in Western Europe. NIS belonging to taxonomically distinct families may interact within ecosystems in unexpected ways such as exploiting vacant niches and exhibiting exotic secondary chemistry that may result in marked differences in tissue decomposition, herbivore tolerance and allelochemistry. This may also be expected, although to a lesser extent, when non-indigenous genera invade ecosystems. To what extent does this reflect the taxonomic composition of the invasive NIS flora? Darwin's naturalization hypothesis proposes that introduced plant species will be less likely to establish a self-sustaining wild population in places with congeneric indigenous species because the introduced plants have to compete with their close relatives, or are more likely to be attacked by native herbivores or pathogens (Darwin, 1859). The hypothesis is supported by analyses of Californian and Australian floras (Rejmánek, 1996, 1998) but not for New Zealand and Hawaii (Daehler, 2001; Duncan \& Williams, 2002). On these oceanic islands congeneric relatives are significantly more, not less, likely to naturalize, perhaps because they share with their native relatives traits that pre-adapt them to their new environment.

Further analyses are clearly warranted, but results to date warn against a complacent attitude towards the ecological equivalence of indigenous and naturalized NIS. Furthermore, even where NIS belong to indigenous genera existing in the introduced range, the taxonomic composition of non-indigenous floras is a distinctly nonrandom sample from the pool of available immigrants (Crawley, 1986; Cadotte \& Lovett-Doust, 2001; Fig. 9). Therefore, whether by introducing non-native families and/or genera or increasing the representation of certain native families and/or genera, invasions are changing the taxonomic diversity of regional floras (Pysek, 1998b). 


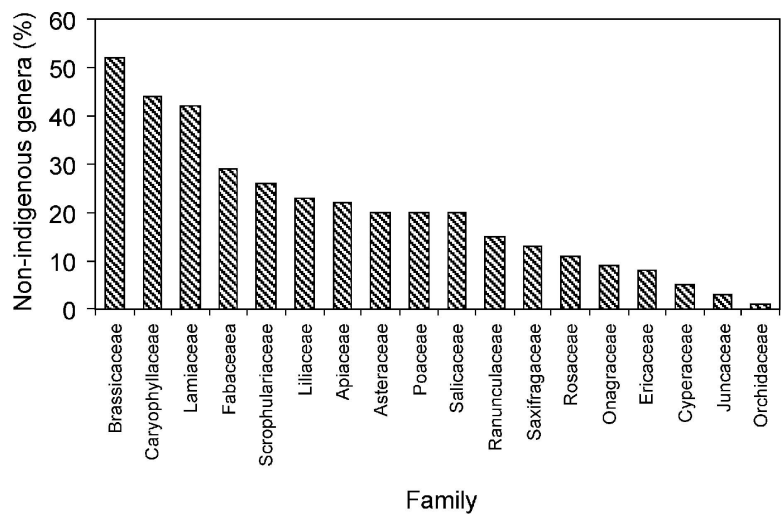

Fig. 9 The percentage of UK plant families comprising nonindigenous species (data from Crawley, 1986).

Thus even where ecological impacts of native and nonnative congeners are similar, the environmental consequences of increased species richness in certain plant families relative to others may not necessarily be trivial. This in itself may warrant a cautious attitude to nonnative introductions until a better understanding has been gained of their impacts on biodiversity and ecosystem function.

\section{Aren't species introductions just as likely to increase species diversity?}

The study of ecosystems impacts arising from plant invasions is still in its infancy and to date most examples are observational rather than experimental. These studies suggest the principle negative impacts of non-indigenous plants on biodiversity are displacement by direct competition, reduced structural diversity, increase in biomass and disruption of the prevailing vegetation dynamics (through shifts in the dominant vegetation life form) of the invaded community (Mack et al., 2000). Plant invasions also affect fire regimes (due to increases in fuel loads), hydrology and nutrient cycling (Parker et al., 1999). However, current understanding of impacts is biased by a disproportionate number of studies on a few key plant species, such as Bromus tectorum, Carpobrotus edulis, Tamarix ramossisima and Lythrum salicaria. Furthermore, examples where plant invasions have resulted in species extinctions are poorly documented.

So what is the expected impact of plant invasions on biodiversity? The British Isles have been fortunate so far in that there is little evidence that introductions have led to species extinctions, and native species are unlikely to be excluded throughout their whole range by nonnative invaders (Manchester \& Bullock, 2000). Rosenzweig (2001) suggested that the breakdown of isolating barriers between biogeographical regions through increased species introductions will not have much effect on species diversity. At a global scale, extinctions will lead to a net loss of species but this may be compensated for by increases in local diversity following expansion of the regional species pool. However, this assertion has been criticized on the grounds that regional speciesarea curves cannot be extrapolated to produce global estimates (Collins et al., 2002). Additionally, this interpretation is scale dependent (Shea \& Chesson, 2002). At relatively large spatial scales (e.g. $>10^{3}$ ha) invasive species may contribute positively to total species richness but at small spatial scales (e.g. $10^{-4}-10^{2}$ ha) invasive plant species may significantly alter the composition of particular habitats, often completely displacing certain species and significantly reducing the abundance of others. Any augmentation of species richness is short-lived and even where invasions do not dramatically alter species richness, they often alter the structure, dominance and evenness of the invaded habitat. Furthermore, at least on oceanic islands, while total species richness may not change following invasion the losses of endemic species that are unique to global biodiversity are not compensated by the additional increase in commensal species. Finally, species richness does not necessarily equate to conservation value or quality of ecosystem services. Many habitats are regarded as being of aesthetic and/or conservation value specifically because biogeographic barriers have resulted in unique but relatively species poor communities (Ratcliffe, 1977).

\section{Conclusions}

Although drawn from examples of plants, the issues covered are relevant to the study of invasions of a wide range of taxa. While considerable progress has been made in documenting the invasion of non-indigenous species and consequent impacts, the time is now right to consolidate current understanding. Significant advances have been made in understanding the pathways of species introduction, which taxa invade and how fast they spread, what makes ecosystems invasible, and the variety of impacts that can occur (Rejmánek et al., in press). While there are certainly considerable challenges ahead (Byers et al., 2002), an assessment of how the problem is being approached reveals that outputs may not always facilitate the management of NIS. Reappraisal of the mapping of species distributions, modelling the role of humans in invasion and developing management tools will contribute significantly towards turning the tide of invasions. Furthermore, it is crucial that public and scientific perceptions of invasions are clarified in order to galvanize and target support to combat the 
threats posed by NIS. This is the goal of the Global Invasive Species Programme (GISP) through their global strategy on invasive alien species (McNeeley et al., 2001) and toolkit of best prevention and management practices (Wittenberg \& Cock, 2001). However, success is only likely to occur where the benefits of management are easily quantified, management strategies are clearly structured around national priorities, and sufficient resources are available. The 'Working for Water' programme in South Africa is an outstanding model of what can be achieved (Van Wilgen et al., 2001). However, much of the frontline of the war against NIS frequently suffers from insufficient resources to combat the threat thoroughly, and it is precisely under these circumstances where targeted scientific insights are most needed.

\section{Acknowledgements}

This paper arises from work funded by the Natural Environment Research Council (GST/02/2631, GST/ 02/1210 \& GST/02/2077). I would like to thank Dave Richardson and two anonymous referees for constructive comments on a previous version of this paper. This paper contributes to the Global Change in Terrestrial Ecosystems-International Geosphere Biosphere Programme and the International Biodivesity Year 2001-2002.

\section{References}

Allen, L.J.S., Allen, E.S., Kunst, C.R.G. \& Sosebee R.E. (1991) A diffusion model for dispersal of Opuntia imbricata (Cholla) on rangeland. Journal of Ecology, 79, 1123-1135.

Bakkenes, M., Alkemade, J.R.M., Ihle, F., Leemans, R. \& Latour J.B. (2002) Assessing effects of forecasted climate change on the diversity and distribution of European higher plants for 2050. Global Change Biology, 8, 390-407.

Baskin, Y. (2002) A Plague of Rats and Rubber Vines. Island Press, Washington, DC, USA.

Beerling, D.J. (1993) The impact of temperature on the northern distribution limits of the introduced species Fallopia japonica and Impatiens glandulifera in north-west Europe. Journal of Biogeography, 20, 45-53.

Beerling, D.J., Bailey, J.P. \& Conolly, A.P. (1994) Biological Flora of the British Isles: Fallopia japonica (Houtt.) Ronse Decraena. Journal of Ecology, 82, 959-979.

Beerling, D.J., Huntley, B. \& Bailey, J.P. (1995) Climate and the distribution of Fallopia japonica: use of an introduced species to test the predictive capacity of response surfaces. Journal of Vegetation Science, 6, 269-282.

Botkin, D.B. (2001) The naturalness of biological invasions. Western North American Naturalist, 61, 261-266.
Brändle, M. \& Brandl, R. (2001) Species richness of insects and mites on trees: expanding Southwood. Journal of Animal Ecology, 70, 491-504.

Bright, C. (1998) Life Out of Bounds: Bioinvasion in a Borderless World. Worldwatch Institute, Washington, DC, USA.

Brundu, G., Brock, J., Camarda, I., Child, L.E. \& Wade, M. (2001) Plant Invasions: Species Ecology and Ecosystem Management. Backhuys Publishers, Leiden, Netherlands.

Byers, J.E., Reichard, S., Smith, C.S., Parker, I.M., Randall, J.M., Lonsdale, W.M., Atkinson, I.A.E., Seasted, T., Chornesky, E., Hayes, D. \& Williamson, M. (2002). Directing research to reduce the impacts of non-indigenous species. Conservation Biology, 16, 630-640.

Cadotte, M.W. \& Lovett-Doust, J. (2001) Ecological and taxonomic differences between native and introduced plants of south-western Ontario. Ecoscience, $8,230-238$

Caffrey, J.M. (2001) The management of giant hogweed in an Irish river catchment. Journal of Aquatic Plant Management, 39, 28-33.

Carter, R.N. \& Prince, S.D. (1988) Distribution limits from a demographic viewpoint. In Plant Population Ecology (eds A.J. Davy, M.J. Hutchings \& A.R. Watkinson), pp. 165-184. Blackwell Scientific Publications, Oxford, UK.

Clark, J., Fastie, C., Hurtt, G., Jackson, S., Johnson, C., King, G., Lewis, M., Lynch, J., Pacala, S., Prentice, C., Schupp, G., Webb, T. \& Wyckoff, P. (1998) Dispersal theory offers solutions to Reid's Paradox of rapid plant migration. BioScience, 48, 13-24.

Collingham, Y.C., Huntley, B. \& Hulme, P.E. (1997) The use of a spatially explicit model to simulate the spread of riparian weeds. In Proceedings of the International Association for Landscape Ecology. Species Dispersal and Land Use Processes (eds A. Cooper \& J. Power), pp. 45-52.

Collingham, Y.C., Wadsworth, R.A., Willis, S.G., Huntley, B. \& Hulme, P.E. (2000) Predicting the spatial distribution of alien riparian species: issues of spatial scale and extent. Journal of Applied Ecology, 37 (Suppl. 1), 13-27.

Collins, M.D., Vazquez, D.P. \& Sanders, N.J. (2002) Species-area curves, homogenisation and the loss of diversity. Evolutionary Ecology Research, 4, 457-464.

Compton, S.G. \& Key, R.S. (1998) Species Action Plan: Lundy Cabbage (Coincya wrightii) and its associated insects. English Nature, Peterborough, UK.

Crawley, M.J. (1986) What makes a community invasible? In Colonization, Succession and Stability (eds A.J. Gray, M.J. Crawley \& P.J. Edwards), pp. 429-453. Blackwell Scientific Publications, Oxford, UK.

Daehler, C.C. (2001) Darwin's naturalization hypothesis revisited American Naturalist, 158, 324-330.

Daehler, C.C. \& Carino, D.A. (2000) predicting invasive plants: prospects for a general screening system based on current regional models. Biological Invasions, 2, 93-102.

Darwin, C. (1859) On the Origin of Species. Murray, London, UK.

Davis, A.J., Jenkinson, L.S., Lawton, J.H., Shorrocks, B. \& Wood, S. (1998) Making mistakes when predicting shifts in species range in response to global warming. Nature, 391, 783-786. 
Dawson, F.H. \& Holland, D. (1999) The distribution in bankside habitats of three alien plants in the UK in relation to the development of control strategies. Hydrobiologia, 415, 193-201.

Department of the Environment (DoE) (1997) The Regulation and Control of the Release of Non-native Animals and Plants into the Wild in Great Britain. Department of the Environment, London, UK

Dickson, J.H., Macpherson, P. \& Watson, K. (2000) The Changing Flora of Glasgow: Urban and Rural Plants through the Centuries. Edinburgh University Press, Edinburgh, UK.

Dodd, F.S., de Waal, L.C., Wade, P.M. \& Tiley, G.E.D.

(1994) Control and management of Heracleum mantegazzianum (Giant hogweed). In Ecology and Management of Invasive Riverside Plants. (eds L.C. de Waal, L.E. Child, P.M. Wade \& J.H. Brock) pp. 111-126. John Wiley, Chichester, UK

Duncan, R.P. \& Williams, P.A. (2002) Darwin's naturalization hypothesis challenged. Nature, 417, 608-609.

Ewel, J.J., O’Dowd, D.J, Bergelson, J., Daehler, C.C., D'Antonio, C.M., Gomez, L.D., Gordon, D.R., Hobbs R.J., Holt, A., Hopper, K.R., Hughes, C.E., Lahart, M., Leakey, R.R.B., Lee, W.G, Loope, L.L., Lorence, D.H., Louda, S.M., Lugo, A.E., McEvoy, P.B., Richardson, D.M. \& Vitousek, P.M. (1999) Deliberate introductions of species: Research needs - benefits can be reaped, but risks are high. BioScience, 49, 619-630.

Franklin, J. (1995) Predictive vegetation mapping: geographic modelling of biospatial patterns in relation to environmental gradients. Progress in Physical Geography, 19, 474-499.

Gilbert, O.L. (1989) The Ecology of Urban Habitats. Chapman \& Hall, London, UK.

Gould, S.J. (2002) I Have Landed: The End of a Beginning in Natural History. Harmony Books, New York, USA.

Gritten, R.H. (1995) Rhododendron ponticum and some other invasive plants in the Snowdonia National Park. In Plant Invasions: General Aspects and Special Problems (eds P. Pysek, K. Prach, M. Rejmánek \& M. Wade), pp. 213-219. SPB Academic Publishing, Amsterdam, Netherlands.

Hannah, L., Carr, J.L. \& Lankerani, A. (1995). Human disturbance and natural habitat: a biome level analysis of a global data set. Biodiversity and Conservation, 4, 128-155.

Headrick, D.H. \& Goeden, R.D. (2001) Biological control as a tool for ecosystem management. Biological Control, 21, 249-257.

Higgins, S.I. \& Richardson, D.M. (1996) A review of models of alien plant spread. Ecological Modelling, 87, 249-265.

Higgins, S.I. \& Richardson, D.M. (1999) Predicting plant migration rates in a changing world: the role of long-distance dispersal. American Naturalist, 153, 464-475.

Higgins, S.I., Richardson, D.M. \& Cowling R.M. (1996) Modeling invasive plant spread: The role of plantenvironment interaction and model structure. Ecology, 77, 2043-2054.

Higgins, S.I., Richardson, D.M. \& Cowling, R.M. (2000) Using a dynamic landscape model for planning the management of alien plant invasions. Ecological Applications, 10, 1833-1848.

HMSO (1981) The Wildlife and Countryside Act 1981. HMSO, London, UK.
Hodkinson, D.J. \& Thompson, K. (1997) Plant dispersal: the role of man. Journal of Applied Ecology, 34, 1484-1496.

Hulme, P.E., Crawley, M.J., Hofgaard, A., Huntley, B., Lurz, P., O'Connell, M., Rushton, S., Schaffner, U., Sykes, M., Vila, M., Watt, A. \& Willis, S.G. (2000) Alien species and outbreaking species in ecosystems. In Terrestrial Ecosystem Research in Europe: Success, Challenges and Policy (eds M.A. Sutton, J.M. Moreno, W.H. van der Putten \& S. Struwe), pp. 44-48. European Commission, Luxembourg.

Jalas, J. \& Suominen, J. (1972-1994) Atlas Florae Europaeae: Distribution of Vascular Plants in Europe. Societas Vanamo, Helsinki, Finland.

Kennedy, C.E.J. \& Southwood, T.R.E. (1984) The number of species of insects associated with British trees: a re-analysis. Journal of Animal Ecology, 53, 455-478.

Lawton, J.H. (2000) Community Ecology in a Changing World. Ecology Institute, Luhe, Germany.

Levine, J.M. \& D'Antonio, C.M. (1999) Elton revisited: a review of evidence linking diversity and invasibility. Oikos, 87, 15-26.

Mack, R.N., Simberloff, D., Lonsdale, W.M., Evans, H., Clout, M. \& Bazzaz, F.A. (2000) Biotic invasions: causes, epidemiology, global consequences, and control. Ecological Applications, 10, 689-710.

Manchester, S.J. \& Bullock, J.M. (2000) The impacts of nonnative species on UK biodiversity and the effectiveness of control. Journal of Applied Ecology, 37, 845-864.

Maron, J.L. \& Vila, M. (2001) When do herbivores affect plant invasion? Evidence for the natural enemies and biotic resistance hypotheses. Oikos, 95, 361-373.

Masters, R.A. \& Sheley, R.L. (2001) Principles and practices for managing rangeland invasive plants. Journal of Range Management, 54, 213-225.

May, R.M. (1989) Levels of organization in ecology. In Ecological Concepts (ed. J. M. Cherrett), pp. 339-363. Blackwell Scientific Publications, Oxford, UK.

McEvoy, P.B. \& Coombs, E.M. (1999) Biological control of plant invaders: Regional patterns, field experiments, and structured population models. Ecological Applications, 9, 387-401.

McFadyen, R.E.C. (1998) Biological control of weeds. Annual Review of Entomology, 43, 369-393.

McNeeley, J.A. (2001) The Great Reshuffling; Human Dimensions of Invasive Alien Species. IUCN, Gland, Switzerland.

McNeeley, J.A., Mooney, H.A., Neville, L.E., Schei, P. \& Waage, J.K. (2001) A Global Strategy on Invasive Alien Species. IUCN, Gland, Switzerland.

Moody, M.E. \& Mack, R.N. (1988) Controlling the spread of plant invasions: the importance of nascent foci. Journal of Applied Ecology, 25, 1009-1021.

Mooney, H.A. \& Hobbs, R.J. (2000) Invasive Species in a Changing World. Island Press, Washington, DC, USA.

Office of Technology Assessment (OTA) (1993) Harmful NonIndigenous Species in the United States. US Government Printing Office, Washington, DC, USA.

Panetta, F.D. \& Mitchell, N.D. (1991) Bioclimatic prediction of the potential distribution of some weed species prohibited entry to New Zealand. New Zealand Journal of Agricultural Research, 34, 341-350.

Parker, I.M., Simberloff, D., Lonsdale, W.M., Goodell, K., Wonham, M., Kareiva, P.M., Williamson, M.H., Von Holle, B., Moyle, P.B., Byers, J.E. \& Goldwasser, L. (1999) Impact: Toward a framework for understanding the ecological effects of invaders. Biological Invasions, 1, 3-19. 
Perring, F.H. \& Walters, S.M. (1976) Atlas of the British Flora (2nd edition). EP Publishing for the Botanical Society of the British Isles, UK.

Perrings, C., Williamson, M. \& Dalmazone, S. (2000) The Economics of Biological Invasions. Edward Elgar, Cheltenham, UK.

Peterson, A.T. \& Vieglais, D.A. (2001) Predicting species invasions using ecological niche modeling: new approaches from bioinformatics attack a pressing problem. BioScience, $\mathbf{5 1}$, 363-371.

Pimentel, D. (2002) Biological Invasions: Economic and Environmental Costs of Alien Plant, Animal, and Microbe Species. CRC Press, Boca Raton, USA.

Pimentel, D., McNair, S., Janecka, J., Wightman, J., Simmonds, C., O'Connell, C., Wong, E., Russel, L., Zern, J., Aquino, T. \& Tsomondo, T. (2001) Economic and environmental threats of alien plant, animal, and microbe invasions Agroecosystems and Environment, 84, 1-20.

Plant Life (2000) At War with Aliens. Plant Life Publications, London, UK.

Preston, C.D, Pearman, D.A. \& Dines, T.D. (2002a) New Atlas of the British and Irish Flora. Oxford University Press, Oxford, UK.

Preston, C.D., Telfer, M.G., Arnold, H.R., Carey, P.D., Cooper, J.M., Dines, T.D., Hill, M.O., Pearman, D.A., Roy, D.B. \& Smart, S.M. (2002b) The Changing Flora of the UK. DEFRA, London, UK.

Pysek, P. (1998a) Alien and native species in Central European urban floras: a quantitative comparison. Journal of Biogeography, 25, 155-163.

Pysek, P. (1998b) Is there a taxonomic pattern to plant invasions? Oikos, 82, 282-294.

Pysek, P., Jarosik, V. \& Kucera, T. (2002) Patterns of invasion in temperate nature reserves Biological Conservation, 104, 13-24.

Radford, I.J. \& Cousens, R.D. (2000) Invasiveness and comparative life-history traits of exotic and indigenous Senecio species in Australia. Oecologia, 125, 531-542.

Ratcliffe, D.A. (1977) A Nature Conservation Review. Cambridge University Press, Cambridge, UK.

Rejmánek, M. (1996) A theory of seed plant invasiveness: the first sketch. Biological Conservation, 78, 171-181.

Rejmánek, M. (1998) Invasive plant species and invadible ecosystems. In Invasive species and biodiversity management (eds O.T. Sandlund, P.J. Schei \& A. Vilken), pp. 79-102. Kluwer, Dordrecht, Netherlands.

Rejmánek, M., Richardson, D.M., Higgins, S.I., Pitcairn, M. \& Grotkopp, E. (in press) Plant invasion ecology: state of the art. In Invasive Alien Species: Searching for Solutions (eds H.A. Mooney, J.A. McNeeley, L. Neville, P.J. Schei \& J. Waage). Island Press, Washington, DC, USA.

Richardson, D.M., Allsopp, N., D'Antonio, C., Milton, S.J. \& Rejmánek, M. (2000). Plant invasions - The role of mutualisms. Biological Reviews, 75, 65-93.

Rosenzweig, M. (2001) The four questions: What does the introduction of exotic species do to diversity? Evolutionary Ecology Research, 3, 361-367.

Sagoff, M. (1999) What's wrong with alien species? Report of the Institute for Philosophy and Public Policy, 19, 16-23.

Sakai, A.K., Weller, S.G., Allendorf, F.W., Holt, J.S., Lodge, D.M., Molofsky, J., With, K.A., Baughman, S., Cabin, R.J., Cohen, J.E., Ellstrand, N.C., McCauley, D.E.,
O'Neil, P., Parker, I.M. \& Thompson, J.N. (2001) The population biology of invasive species. Annual Review of Ecology and Systematics, 32, 30532.

Sampson, C. (1994) Cost and impact of current control methods used against Heracleum mantegazzianum (Giant Hogweed) and the case for investigating biological control. In Ecology and Management of Invasive Riverside Plants. (eds L.C. de Waal, L.E. Child, P.M. Wade \& J.H. Brock), pp. 55-65. John Wiley, Chichester, UK.

Shea, K. \& Chesson, P. (2002) Community ecology theory as a framework for biological invasions. Trends in Ecology and Evolution, 17, 170-176.

Shine, C., Williams, N. \& Gundling, L. (2000) A Guide to Designing Legal and Institutional Frameworks on Alien Invasive Species. IUCN, Gland, Switzerland.

Slobodkin, L.B. (2001). The good, the bad and the reified. Evolutionary Ecology Research, 3, 1-13.

Smith, M.D. \& Knapp, A.K. (2001) Physiological and morphological traits of exotic, invasive exotic, and native plant species in tallgrass prairie. International Journal of Plant Science, 162, 785-792.

Smith, C.S, Lonsdale, W.M. \& Fortune, J. (1999) When to ignore advice: invasion predictions and decision theory. Biological Invasions, 1, 89-96.

Sykes, M.T. (2001) Modelling the potential distribution and community dynamics of lodgepole pine (Pinus contorta Dougl. ex. Loud.) in Scandinavia. Forest Ecology \& Management, 141, 69-84.

Thompson, K., Hodgson, J.G. \& Rich, T.C.G. (1995) Native and alien invasive plants: more of the same? Ecography, 18, 390-402.

Tiley, G.E.D. \& Philp, B. (1994) Heracleum mantegazzianum (Giant Hogweed) and its control in Scotland. In Ecology and Management of Invasive Riverside Plants. (eds L.C. de Waal, L.E. Child, P.M. Wade \& J.H. Brock), pp. 101-109. John Wiley, Chichester, UK.

Trueman, I., Morton, A. \& Wainwright, M. (1995) The Flora of Montomeryshire. The Montgomeryshire Field Society and The Montgomeryshire Wildlife Trust, Welshpool, UK.

USDA \& NRCS (2002) The PLANTS Database. Version 3.5 (http://plants.usda.gov). National Plant Data Center, Baton Rouge, USA.

Van Wilgen, B.W., Richardson, D.M., Le Maitre, D.C, Marais, C. \& Magadlela, D. (2001) The economic consequences of alien invasions: Examples of impacts and approaches for sustainable management in South Africa. Environment, Development and Sustainability, 3, 145-168.

Wadsworth, R.A., Collingham, Y.C., Willis, S.G., Huntley, B. \& Hulme, P.E. (2000) Simulating the spread and management of alien riparian weeds: are they out of control? Journal of Applied Ecology, 37 (suppl. 1), 28-38.

Welch, D., Carss, D.N., Gornall, J., Manchester, S.J., Marquiss, M., Preston, C.D., Telfer, M.G., Arnold, H. \& Holbrook, J. (2001) An Audit of Alien Species in Scotland. Scottish Natural Heritage Review 139, Edinburgh, UK.

Williamson, M. (1996) Biological Invasions. Chapman \& Hall, London, UK.

Willis, S.G \& Hulme, P.E. (2002) Does temperature limit the invasion of Impatiens glandulifera and Heracleum mantegazzianum: in the UK? Functional Ecology, 16, 530-539. 
Wilson, E.O. (1992) The Diversity of Life. Belknap Press, Cambridge, USA.

Wilson, J.B., Rapson, G.L., Sykes, M.T., Watkins, A.J. \& Williams, P.A. (1992) Distributions and climatic correlations of some exotic species along roadsides in South Island, New Zealand. Journal of Biogeography, 19, 183-193.

Wittenberg, R. \& Cock, M.J.W. (eds) (2001) Invasive Alien Species: A Toolkit for Best Prevention and Management Practices. CAB International, Wallingford, UK [also available at http:/ / www.cabi-bioscience.ch/wwwgisp, accessed 1 April 2004].

Woodward, F.I. (1987) Climate and Plant Distribution. Cambridge University Press, Cambridge, UK.

\section{Biographical sketch}

Philip Hulme is Head of the Ecosystem dynamics Section at the NERC Centre for Ecology and Hydrology, Banchory, Scotland. He currently manages several large-scale projects on plant invasions in regions as diverse as the Arctic tundra, Scottish glens, Mediterranean islands and the semi-arid tropics. He is secretary of the British Ecological Society's Invasive Species Specialist Group and is a member of the UK Government's Advisory Committee on Releases to the Environment. 